\title{
Cardiac Biomarkers as Indicators of Hemodynamic Adaptation during Postasphyxial Hypothermia Treatment
}

\author{
D.C. Vijlbrief ${ }^{a}$ M.J.N.L. Benders ${ }^{a} \quad$ H. Kemperman ${ }^{b} \quad$ F. van Bel ${ }^{a} \quad$ W.B. de Vries ${ }^{a}$ \\ ${ }^{\mathrm{a}}$ Departments of Neonatology and ${ }^{\mathrm{b}} \mathrm{Clinical}$ Chemistry and Hematology, University Medical Center \\ Utrecht/Wilhelmina Children's Hospital, Utrecht, The Netherlands
}

\section{Key Words}

B-type natriuretic peptide $\cdot$ Cardiac troponin-I $\cdot$ Asphyxia neonatorum $\cdot$ Hypothermia $\cdot$ Biological markers

\begin{abstract}
Background: Little is known about the effects of hypothermia on the cardiovascular system in term newborns with neonatal encephalopathy. Objectives: To evaluate whether mild hypothermia for neonatal encephalopathy is cardioprotective as indicated by the cardiac biomarkers cardiac troponin I (CTnl) and B-type natriuretic peptide (BNP). Methods: This was an observational cohort study of infants treated for perinatal asphyxia. In infants, mild total body hypothermia treatment of $33.5^{\circ} \mathrm{C}$ during $72 \mathrm{~h}$ was initiated $(\mathrm{n}=$ 20). Samples of cTnl and BNP were collected before the start of hypothermia, at 24 and $48 \mathrm{~h}$ after birth, and after rewarming ( $84 \mathrm{~h}$ ). BNP and cTnl values were then compared with BNP and $c T n l$ values of asphyxiated infants not treated with hypothermia $(n=28)$. Results: No differences were found between the groups in clinical patient characteristics or inotropic support. The hypothermia-treated patients seemed to be clinically more affected (5-min Apgar score, $p<0.05$; umbilical artery $\mathrm{pH}, \mathrm{p}=0.08$ ), but showed similar encephalopathy scores. Significantly lower values for BNP were found in hypothermia-compared to nonhypothermia-treated infants at $48 \mathrm{~h}$ and at normothermia after rewarming [144 pmol/I
\end{abstract}

(95-286) vs. $75 \mathrm{pmol} / \mathrm{l}(45-143), 182 \mathrm{pmol} / \mathrm{l}(73-341)$ vs. 43 $\mathrm{pmol} / \mathrm{l}$ (24-163)]. No differences were found for cTnl concentrations between both groups. Conclusions: The raised, but similar, cTnl values between hypothermia- and nonhypothermia-treated infants indicate similar myocardial damage in both groups. The lower BNP levels during hypothermia treatment suggest that hypothermia after perinatal asphyxia exerts a beneficial effect on cardiac function.

Copyright $\odot 2012$ S. Karger AG, Basel

\section{Introduction}

Perinatal asphyxia is associated with high mortality and morbidity. Recent studies have shown improved outcome after mild hypothermia treatment for neonatal encephalopathy [1]. This makes hypothermia the only established treatment for neonatal encephalopathy at this moment. B-type natriuretic peptide (BNP) is an endogenous peptide hormone secreted by cardiac ventricles in response to increased wall stress and ventricular filling pressure. It causes vasodilatation and has a diuretic and natriuretic effect. BNP is used in infants to identify significant patent ductus arteriosus and to diagnose cardiovascular disease, such as persistent pulmonary hypertension of the newborn (PPHN) [2-4]. BNP concentrations in plasma correspond well with echocardiographic find-

\section{KARGER \\ Fax +4161306 1234 \\ E-Mail karger@karger.ch}

www.karger.com (c) 2012 S. Karger AG, Basel

$1661-7800 / 12 / 1024-0243 \$ 38.00 / 0$

Accessible online at:

www.karger.com/neo
Willem B. de Vries, MD, PhD

Department of Neonatology

University Medical Center Utrecht/Wilhelmina Children's Hospital

Room No. KE.04.123.1, PO Box 85090, NL-3508 AB Utrecht (The Netherlands)

Tel. +31 88755 4545, E-Mail w.b.devries-3@umcutrecht.nl 
ings of ventricular strain in children with heart failure [5]. Troponin is an inhibitory protein complex located on the actin filament in all striated muscle and consists of three subunits: T, C, and I. Previous studies have shown elevated levels of cardiac troponin I (cTnI) in asphyxiated neonates. cTnI is thought to be an indicator of perinatal asphyxia-induced myocyte damage [6]. cTnI correlates strongly with the clinical grade of encephalopathy [7]. Hypothermia is linked to reduced cardiac output, peripheral vasoconstriction, sinus bradycardia, cardiac arrhythmias, hypotension, platelet dysfunction, and increased blood viscosity [8-11]. A study in newborn pigs showed a cardioprotective effect of hypothermia; whether this is also true in human infants is not clear [12]. Our study was done to investigate whether mild hypothermia exerts a beneficial effect on the heart after perinatal asphyxia using the cardiac biomarkers cTnI and BNP.

\section{Methods}

Study Design

This study was carried out in the neonatal intensive care unit at the University Medical Center Utrecht from December 2006 to October 2008. The study was started before the introduction of hypothermia to assess the cardiac function of infants after perinatal asphyxia and was continued when hypothermia treatment was introduced in February 2008. Those infants admitted before the introduction of hypothermia as a treatment served as the nonhypothermia-treated group. Patients were eligible if they were born at or after 36 completed weeks of gestation. Criteria related to the identification of perinatal asphyxia and encephalopathy are shown in table 1. Hypothermia treatment was started within $6 \mathrm{~h}$ after birth. Infants with major congenital malformations or known chromosomal abnormalities were excluded from the study. Parental consent was obtained in all cases. This study was conducted following the guidelines of the local medical ethics committee.

Patient characteristics and clinical data were collected prospectively. To assess the intensity of blood pressure support, a blood pressure support scoring system was used, depending on the intensity of the treatment necessary (score 0: no treatment; score 1: volume expansion and/or dopamine $\leq 5 \mu \mathrm{g} / \mathrm{kg} / \mathrm{min}$; score 2 : dopamine $>5$ but $\leq 10 \mu \mathrm{g} / \mathrm{kg} / \mathrm{min}$; score 3 : dopamine $>10$ $\mu \mathrm{g} / \mathrm{kg} / \mathrm{min}$ or dopamine + dobutamine $\leq 10 \mu \mathrm{g} / \mathrm{kg} / \mathrm{min}$; score 4 : dopamine + dobutamine $>10 \mu \mathrm{g} / \mathrm{kg} / \mathrm{min}$; score 5: additional adrenaline and/or corticosteroids) [13]. The blood pressure score and heart rate was registered at the time of sampling for BNP and cTnI.

Blood was collected at admission $(<6 \mathrm{~h})$, at 24 and $48 \mathrm{~h}$ after birth, and at $84 \mathrm{~h}$ (normothermia).

Echocardiography was performed if cardiac abnormalities were suspected or if there was a clinical indication, such as suspected persistent pulmonary hypertension, therapy-resistant hypotension, cardiac murmur, or persistent low oxygen saturations. PPHN was defined as hypoxemia with echocardiographic find-
Table 1. Study entry criteria

Gestational age $\geq 36$ weeks

AND

Perinatal asphyxia

- Apgar 5 min $\leq 5$

or

- Resuscitation/ventilation during 10 min after birth or

- Umbilical artery $\mathrm{pH}<7.0$ and 'base deficit' $>16 \mathrm{mmol} / \mathrm{l}$ or

- lactate $>10.0 \mathrm{mmol} / \mathrm{l}<1 \mathrm{~h}$ after birth

AND

Encephalopathy

- Clinical: Thompson score $>7$ between 1 and $3 \mathrm{~h}$ after birth or

- aEEG: normal background with some seizure activity, moderately abnormal activity, suppressed activity or continuous seizure activity

AND

Admission $<6 \mathrm{~h}$ after birth

$\mathrm{aEEG}=$ Amplitude-integrated electroencephalography.

ings of elevated pulmonary artery pressure and/or right-to-left shunting through a patent foramen ovale or the patent ductus arteriosus. Clinical treatment was left to the discretion of the attending neonatologist, following standardized protocols.

Hypothermia patients were treated with total body cooling according to our hypothermia protocol using the Criticool ${ }^{\mathrm{TM}}$ device (MTRE, Milton Keynes, UK). Infants were wrapped into a bodyshaped 3-dimensional garment upon admission to our neonatal intensive care unit. If infants were transported from another hospital, there was no active rewarming during transport. Mild hypothermia was started within $6 \mathrm{~h}$ after birth and maintained for $72 \mathrm{~h}$. Patients were kept at $33.5^{\circ} \mathrm{C}$; the temperature was servocontrolled with a thermometer probe rectally placed. When a period of $72 \mathrm{~h}$ was completed, rectal temperature was allowed to rise $0.5^{\circ} \mathrm{C} / \mathrm{h}$ until normothermia $\left(36.5^{\circ} \mathrm{C}\right)$ was achieved. This temperature $\left(36.5^{\circ} \mathrm{C}\right)$ was maintained during $24 \mathrm{~h}$. After this period, the garment was removed and normothermia was achieved according to standard infant protocol until discharge.

\section{$B N P$ and $c \operatorname{TnI}$ Measurements}

Blood samples were collected from an arterial catheter or by capillary samples (heel stick) into a standard collection vial with ethylenediaminetetraacetic acid (EDTA) for BNP and lithium heparin (Capijet ${ }^{\circledR}$; VWR, West Chester, Pa., USA) for cTnI. BNP and CTnI were analyzed directly after collection on a DxI $800 \mathrm{im}$ munochemistry system (Beckman Coulter Diagnostics, Brea, Calif., USA). The lower limit of detection for this assay is $5 \mathrm{pmol} / \mathrm{l}$ for BNP and $0.01 \mu \mathrm{g} / \mathrm{l}$ for cTnI. Maintenance and quality performance of the instrument were followed according to company instructions. Blood samples were simultaneously collected with other routine bloodwork. 
Table 2. Characteristics of patients treated with hypothermia and without hypothermia

\begin{tabular}{lccc}
\hline & Normothermia $(\mathrm{n}=28)$ & Hypothermia $(\mathrm{n}=20)$ & $\mathrm{p}$ \\
\hline Birth weight, g & $3,333(2,030-4,360)$ & $3,902(3,010-5,000)$ & 0.10 \\
Gestational age, weeks & $40.5(36.4-42.3)$ & $40.2(39-41.9)$ & 0.54 \\
Birth & & & 1.00 \\
$\quad$ Meconium-stained amniotic fluid, $\mathrm{n}$ & 14 & 11 & 0.99 \\
$\quad$ Caesarean section, $\mathrm{n}$ & 17 & 10 & 0.74 \\
Hospital birth, \% & 97 & 85 & 0.85 \\
Male, \% & 52 & 75 & 0.03 \\
Apgar score at 5 min & $5(0-8)$ & $3(0-7)$ & 0.06 \\
Umbilical artery pH & $6.99(6.75-7.21)$ & $6.82(6.64-7.25)$ & 0.09 \\
Base deficit, mmol/l & $15.4(7-25)$ & $19.4(10-24)$ & 0.43 \\
Lactate, mmol/l & $10.8(2-33.7)$ & $14.9(4.8-28.7)$ & 0.74 \\
Mechanical ventilation, \% & 79 & 86 & 0.96 \\
PPHN/nitric oxide, $\mathrm{n}$ & 6 & 5 & 0.36 \\
Inotropic support score & 2.6 & 2.8 & 0.19 \\
Encephalopathy & & & 0.09 \\
$\quad$ Sarnat & 2 & 2 & 0.11 \\
$\quad$ Thompson & 10 & 11.5 & 0.25 \\
Seizures, \% & 52 & 75 & 9 \\
Mortality, n & 8 & &
\end{tabular}

\section{Statistics}

Descriptive data are presented as medians with absolute range; $\mathrm{BNP}$ and cTnI levels are presented as medians with interquartile range. There were no missing data at any of the mentioned time points. Comparison of the groups was done by nonparametric statistical analyses using the Mann-Whitney U test. Spearman's rank-sum test was used to correlate BNP to associated variables. The statistical analysis took multiple comparisons and repeated measures into account. The distribution of BNP and cTnI values was illustrated by box- and-whisker plots. A p value of $<0.05$ was considered significant. For the statistical analysis, Predictive Analytics SoftWare Statistics 17.0 (IBM SPSS, Armonk, N.Y., USA) was used.

\section{Results}

\section{Patient Characteristics}

In total, 48 infants were included in the study, 28 in the nonhypothermia- and 20 in the hypothermia-treated group. Patients' characteristics of both groups are shown in table 2. There were no significant differences between the groups in birth weight, gestational age, gender, or race. There were no significant differences in asphyxiarelated criteria, such as serum lactate levels, at admission between the groups. There were no significant differences between the groups in the total amount of resuscitation needed, inotropic support, or occurrence of PPHN. In hypothermia-treated infants, a lower Apgar score at 5 min [median 5 (range: $0-8$ ) vs. $3(0-7)$; p < 0.05] and a trend towards a lower umbilical artery $\mathrm{pH}$ [median 6.99 (range: 6.75-7.21) vs. 6.82 (6.64-7.24); $\mathrm{p}=0.08$ ] was found. The level of encephalopathy on admission was similar between the groups. The median clinical encephalopathy grade (Sarnat classification) was 2 in both groups (range: 1-3); the median Thompson score was not significantly different between the nonhypothermia- and hypothermia-treated group [median 11.5 (range: 8-19) vs. 10 (419); $\mathrm{p}=0.10$ ] [14]. There were more infants with seizures in the hypothermia-treated group (52 vs. 75\%; $\mathrm{p}=0.11$ ), although this difference was not statistically significant. Mortality was similar between the two groups.

\section{Pattern of BNP}

The study showed increased BNP levels in both groups, nonhypothermia-treated versus hypothermia-treated, after perinatal asphyxia as compared to the normal reference range for term infants described in the literature (day 0-1, 67 pmol/1; day 4-6, 14 pmol/l) [15]. At admission and at $24 \mathrm{~h}$ after birth, no significant differences were found between the nonhypothermia- versus the hypothermiatreated group [200 pmol/1 (61-1,072) vs. $285 \mathrm{pmol} / 1$ (24908), $186 \mathrm{pmol} / \mathrm{l}(112-415)$ vs. $230 \mathrm{pmol} / \mathrm{l}(77-1,022)$, respectively]. We found a significantly lower BNPlevel in the 


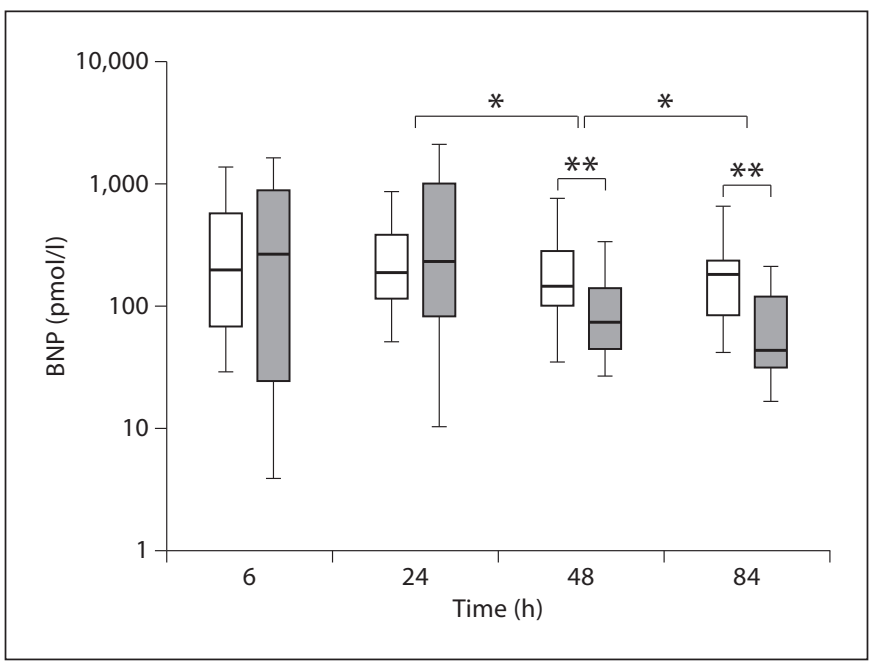

Fig. 1. Box-whisker plot comparing hypothermia-treated patients (grey) and nonhypothermia-treated patients (blank) for BNP serum levels in a logarithmic scale at specified time points. Horizontal lines indicate median values, boxes indicate the 25 th to 75th percentile range, and outer whiskers indicate the 5th to 95th percentile range. ${ }^{*} \mathrm{p}<0.05$ decrease in hypothermia-treated infants at 24 vs. $48 \mathrm{~h}$ and 48 vs. $84 \mathrm{~h} ;{ }^{* *} \mathrm{p}<0.05$ hypothermia- vs. nonhypothermia-treated infants at 48 and $84 \mathrm{~h}$.

hypothermia-treated group as compared to the nonhypothermia-treated group at $48 \mathrm{~h}$ after birth and after rewarming [144 pmol/l (95-286) vs. $75 \mathrm{pmol} / \mathrm{l}(45-143), 182$ $\mathrm{pmol} / \mathrm{l}$ (73-341) vs. $43 \mathrm{pmol} / \mathrm{l}(24-163), \mathrm{p}<0.05$, respectively]. Furthermore, in the hypothermia-treated group we found a significant $(\mathrm{p}<0.05)$ decrease in BNP levels after $24 \mathrm{~h}$. The nonhypothermia-treated group showed relatively steady median BNP levels (fig. 1). No significant correlations were found between BNP and possible confounders, such as changes in heart rate, PPHN, epinephrine use at resuscitation, or hypotension treatment.

\section{Pattern of cTnI}

cTnI levels in both groups were elevated compared to the normal reference range for term infants described in the literature (day 0, $0.3 \mu \mathrm{g} / \mathrm{l}$; day $3,0.1 \mu \mathrm{g} / \mathrm{l}$ ), as is expected in patients after perinatal asphyxia [16]. As shown in figure 2, we found no difference in cTnI serum levels between the groups at the various points of time. No significant correlations were found between cTnI and possible confounders.

\section{Echocardiography}

During our study in 29 infants, echocardiographic measurements were performed simultaneously with BNP

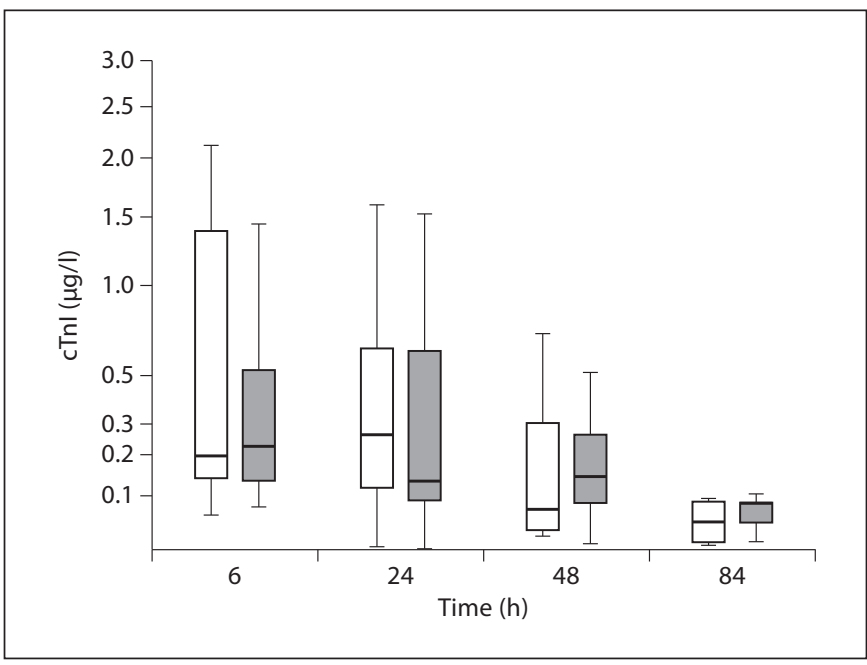

Fig. 2. Box-whisker plot comparing hypothermia-treated patients (grey) and nonhypothermia-treated patients (blank) for cTnI serum levels in a semilogarithmic scale at specified time points. Horizontal lines indicate median values, boxes indicate the 25 th to 75 th percentile range, and outer whiskers indicate the 5 th to 95th percentile range.

and cTnI measurements (10 in nonhypothermia-treated infants, 19 in hypothermia-treated infants). The measurements were taken at $24 \mathrm{~h}$ and included the presence of valve regurgitation (especially tricuspid valve regurgitation), cardiac function measurements with fractional shortening and stroke volume, the presence of pulmonary hypertension, patent ductus arteriosus, and internal dimensions of left and right ventricle. We found BNP correlated with echocardiographic measurements representing ventricular volume (left ventricular internal dimension during diastole and systole $(\mathrm{r}=0.57, \mathrm{p}=0.006 ; \mathrm{r}=$ $0.55, p=0.008$ ), end-diastolic, and end-systolic volumes $(\mathrm{r}=0.56, \mathrm{p}=0.007 ; \mathrm{r}=0.56, \mathrm{p}=0.007)$. No correlations were found between $\mathrm{cTnI}$ and echocardiographic measurements.

\section{Discussion}

In our study we found a significant decrease in BNP levels from $24 \mathrm{~h}$ after birth in hypothermia-treated infants. This was not found in nonhypothermia-treated infants after perinatal asphyxia. Furthermore, we found BNP levels to be lower in the hypothermia-treated groups at 48 and $84 \mathrm{~h}$ after birth. The similar but raised levels of 
cTnI in hypothermia and nonhypothermia-treated infants indicate similar hypoxia-induced myocardial damage in both groups. The decrease in BNP during hypothermia treatment suggests that hypothermia after perinatal asphyxia exerts a beneficial effect on cardiac function. To our knowledge this is the first clinical study comparing cardiac biomarkers between hypothermia and nonhypothermia-treated infants after perinatal asphyxia.

BNP is released by the cardiac ventricles in response to physical stress. Stress can be ventricular wall expansion, pressure overload, or increased wall tension. BNP is involved in the regulation of systemic blood pressure by countering the effects of the renin-angiotensin system and other vasoconstricting neurohormonal systems through a cyclic guanosine monophosphate second messenger. BNP has therefore been established as an accurate indicator of cardiovascular disease in infants and children [17]. BNP levels are closely related to myocardial dysfunction as diagnosed by echocardiography $[18,19]$. We found BNP levels to correlate with echocardiographic parameters representing ventricular size and volume. However, echocardiographic evaluation was not a standard part of our study and the infants were not evaluated with every biomarker measurement. Therefore, it is possible that infants with more circulatory instability were evaluated by echocardiography and the correlation is only valid for those infants. As heart rate is lower in infants treated with hypothermia, it is possible that this poses less stress on the heart resulting in lower BNP levels [9]. In our study we could not find a correlation between changes in heart rate and BNP levels. Moreover, the differences between BNP levels were also found at normothermia when heart rate differences are no longer present.

Gebauer et al. [8] described the cardiac performance using Doppler echocardiography during mild hypothermia after perinatal asphyxia and rewarming. They found that cardiac output was reduced during hypothermia. Tissue perfusion and oxygenation seemed to remain sufficient, as lactate levels did not increase during hypothermia treatment. The cardiac adaptation to lower cardiac output and higher peripheral vascular resistance might explain the initial rise of BNP levels in hypothermiatreated patients, but no difference was found between the hypothermia- and nonhypothermia-treated group at $24 \mathrm{~h}$. Thus, the initial increase in BNP is more likely related to the cardiac adaptation after perinatal asphyxia. As echocardiography was not a standardized part of our study, we cannot relate the reduction in cardiac output

Cardiac Biomarkers during Postasphyxial Hypothermia and increased vascular resistance to BNP levels. Previous studies have shown that BNP levels are very accurate in representing cardiac function $[2,5]$. It is possible that cardiac function, after an initial adaptation, recovers faster in hypothermia-treated patients because of the lower metabolic demand of the body during hypothermia.

Reynolds et al. [2] reported elevated levels of BNP in infants with PPHN. Falling BNP levels during hypothermia treatment may reflect improving pulmonary pressure, rather than a protective effect of the treatment. Furthermore, PPHN has been reported as a possible complication during hypothermia treatment [11]. However, we have not found a difference between the groups in PPHN occurrence, neither clinically nor subclinically as diagnosed by echocardiography.

The use of cTnI after perinatal asphyxia as an indicator of myocardial damage was debated in several articles, as slow skeletal muscle troponin I is the predominant form during fetal development [20]. However, Bodor et al. [21] showed that cTnI is exclusive to the myocardium and therefore elevated levels of cTnI must be of cardiac origin. High levels of cTnI were found in this study in perinatal asphyxiated patients, as was found by others as well [6]. The similar cTnI levels at $6 \mathrm{~h}$ suggest that the severity of hypoxia-induced cardiac myocyte damage was comparable in both groups. From the present study, however, it cannot be concluded that hypothermia has no effect on ongoing cardiac injury after asphyxia. Roka et al. [22] suggested that systemic hypothermia may protect against cell necrosis and tissue dysfunction of the internal organs after neonatal asphyxia. In an animal study, lower levels of cTnI were found in hypothermia-treated newborn pigs [12]. In real life, unlike in the laboratory, insults are not clearly defined. Injury may begin hours before birth and can involve repeated and prolonged periods of hypoxia. Thus, cardiac injury may already be evolving at the time of birth, leading to an absent or relatively shorter period of possible intervention [23].

The nonhypothermia-treated patients in this study were included before mild hypothermia was available as an established treatment modality for perinatal asphyxia. It is possible that during the course of time, apart from the introduction of hypothermia, clinical management of infants has changed. To our knowledge, the treatment of nonhypothermia patients was comparable to the hypothermia-treated group, particularly with regard to fluid management. The use of cTnI and BNP is part of the standard clinical care in perinatal asphyxia patients and of course a double blinded study is impossible to perform. This is a limitation of this study. 
We conclude that a significant decline and lower BNP levels in hypothermia-treated infants suggest a protective effect of hypothermia on cardiac function. Lower BNP levels suggest less myocardial strain during mild hypothermia and the early decline suggests less impairment of cardiac function after perinatal asphyxia. Whether myocardial damage, as represented by cTnI, is affected or reduced by hypothermia treatment cannot be proven in this study. Future investigations should be directed to- wards further elucidating the effect of hypothermia on cardiac damage and function after perinatal asphyxia and the relation of cardiac damage and function to longterm outcome.

\section{Disclosure Statement}

There are no financial relatinships or conflicts of interst to disclose.

\section{References}

1 Jacobs S, Hunt R, Tarnow-Mordi W, Inder T, Davis P: Cooling for newborns with hypoxic ischaemic encephalopathy. Cochrane Database Syst Rev 2007;4:CD003311.

2 Reynolds EW, Ellington JG, Vranicar M, Bada HS: Brain-type natriuretic peptide in the diagnosis and management of persistent pulmonary hypertension of the newborn. Pediatrics 2004;114:1297-1304.

3 Vijlbrief DC, Benders MJ, Kemperman H, van BF, de Vries WB: B-type natriuretic peptide and rebound during treatment for persistent pulmonary hypertension. J Pediatr 2012;160:111-115.

4 Czernik C, Lemmer J, Metze B, Koehne PS, Mueller C, Obladen M: B-type natriuretic peptide to predict ductus intervention in infants $<28$ weeks. Pediatr Res 2008;64:286290.

5 Abassi Z, Karram T, Ellaham S, Winaver J, Hoffman A: Implications of the natriuretic peptide system in the pathogenesis of heart failure: diagnostic and therapeutic importance. Pharmacol Ther 2004;102:223-241.

-6 Trevisanuto D, Picco G, Golin R, Doglioni N, Altinier S, Zaninotto M, Zanardo V: Cardiac troponin I in asphyxiated neonates. Biol Neonate 2006;89:190-193.

7 Shastri AT, Samarasekara S, Muniraman H, Clarke P: Cardiac troponin I concentrations in neonates with hypoxic-ischaemic encephalopathy. Acta Paediatr 2012;101:26-29.

>8 Gebauer CM, Knuepfer M, Robel-Tillig E, Pulzer F, Vogtmann C: Hemodynamics among neonates with hypoxic-ischemic encephalopathy during whole-body hypother$\mathrm{mia}$ and passive rewarming. Pediatrics 2006; 117:843-850.
-9 Thoresen M, Whitelaw A: Cardiovascular changes during mild therapeutic hypothermia and rewarming in infants with hypoxicischemic encephalopathy. Pediatrics 2000; 106:92-99.

10 Christensen RD, Sheffield MJ, Lambert DK, Baer VL: Effect of therapeutic hypothermia in neonates with hypoxic-ischemic encephalopathy on platelet function. Neonatology 2011;101:91-94.

11 Eicher DJ, Wagner CL, Katikaneni LP, Hulsey TC, Bass WT, Kaufman DA, Horgan MJ, Languani S, Bhatia JJ, Givelichian LM, Sankaran K, Yager JY: Moderate hypothermia in neonatal encephalopathy: safety outcomes. Pediatr Neurol 2005;32:18-24.

12 Liu X, Tooley J, Marit LE, Suleiman MS, Thoresen M: Immediate hypothermia reduces cardiac troponin I following hypoxic-ischemic encephalopathy in newborn pigs. Pediatr Res 2011;70:352-356.

13 Krediet TG, Valk L, Hempenius I, Egberts J, van Bel F: Nitric oxide production and plasma cyclic guanosine monophosphate in premature infants with respiratory distress syndrome. Biol Neonate 2002;82:150-154.

14 Thompson CM, Puterman AS, Linley LL, Hann FM, van der Elst CW, Molteno CD, Malan AF: The value of a scoring system for hypoxic ischaemic encephalopathy in predicting neurodevelopmental outcome. Acta Paediatr 1997;86:757-761.

15 Koch A, Singer H: Normal values of B type natriuretic peptide in infants, children, and adolescents. Heart 2003;89:875-878.

16 Turker G, Babaoglu K, Gokalp AS, Sarper N, Zengin E, Arisoy AE: Cord blood cardiac troponin I as an early predictor of short-term outcome in perinatal hypoxia. Biol Neonate 2004;86:131-137.
17 Law YM, Hoyer AW, Reller MD, Silberbach M: Accuracy of plasma B-type natriuretic peptide to diagnose significant cardiovascular disease in children: the Better Not Pout Children! Study. J Am Coll Cardiol 2009;54: 1467-1475.

18 El-Khuffash A, Molloy EJ: Are B-type natriuretic peptide (BNP) and N-terminal-proBNP useful in neonates? Arch Dis Child Fetal Neonatal Ed 2007;92:F320-F324.

19 El-Khuffash A, Davis PG, Walsh K, Molloy EJ: Cardiac troponin $\mathrm{T}$ and $\mathrm{N}$-terminal-pro$B$ type natriuretic peptide reflect myocardial function in preterm infants. J Perinatol 2008; 28:482-486.

20 Gaze DC, Collinson PO: Interpretation of cardiac troponin measurements in neonates - the devil is in the details. Biol Neonate 2006;89:194-196.

21 Bodor GS, Porterfield D, Voss EM, Smith S, Apple FS: Cardiac troponin-I is not expressed in fetal and healthy or diseased adult human skeletal muscle tissue. Clin Chem 1995;41:1710-1715.

22 Roka A, Vasarhelyi B, Bodrogi E, Machay T, Szabo M: Changes in laboratory parameters indicating cell necrosis and organ dysfunction in asphyxiated neonates on moderate systemic hypothermia. Acta Paediatr 2007; 96:1118-1121.

23 de Haan HH, Gunn AJ, Williams CE, Gluckman PD: Brief repeated umbilical cord occlusions cause sustained cytotoxic cerebral edema and focal infarcts in near-term fetal lambs. Pediatr Res 1997;41:96-104. 